\title{
Multi-objective optimization investigation of natural gas engine operating parameters using model-based methodologies
}

\author{
Yinjie Ma ${ }^{1}$, Ronghua Huang ${ }^{1, *}$ and Wei Cheng ${ }^{2}$ \\ ${ }^{1}$ State Key Laboratory of Coal Combustion, Huazhong University of Science and Technology, \\ Wuhan 430074, China \\ 2 Dongfeng Commercial Vehicle Technical Center, Wuhan 430056, China \\ *rhhuang@hust.edu.cn
}

\begin{abstract}
Keywords: Internal-combustion engine; Natural gas; Parameter optimization; Approximate model; Global optimization

Abstract: In order to improve the comprehensive performance of a heavy-duty natural gas engine, the paper developed a strategy to efficiently optimize operating parameters. An approximate mathematical model, which the input control variables were air-fuel ratio and ignition advance angle while the output response were a set of eight core indicators of characterizing the whole performance of engine, was established using response surface method and further validated by test results. A multi-objective and multi-variable optimization function was built with a compromise consideration between the power, economy, emission and thermal load of the engine. The optimal operating parameters under all conditions were obtained by the global optimization with multi-island genetic algorithm. The comparison results showed that, with optimal operating parameters, the engine maintained its original power, but with the drop in gas consumption rate $(1.11 \%)$, maximum combustion temperature (1.46\%) and NOx emission (97.45\%).
\end{abstract}

\section{Introduction}

Natural gas (NG) is getting more and more attention as a potential alternative fuel for automobiles due to its abundant reserves and combustion cleanliness. The development of natural gas engine is also received much attention around the world [1]. Due to its high octane number and low flame propagation velocity, NG engines always face the problems like low power output, high thermal load and high exhaust temperature. Moreover, the Nox emission is also hard to meet the emission standard in some conditions, which the high concentration of input NG is required to achievethe power factor requirement [2]. By precise calibrating the control parameters, air-fuel ratio and ignition advance angle, and optimizing the combution process, the comprehensive performance of the NG engine could be improved from its source.

Recently, the calibration technology which based on model-based methodologies has developed rapidly, and has been gradually used in the optimization of control parameters in engines. The method usually covers the following major process: experimental design, sample collection data modeling and global optimization [3]. Montgomery et al. [4] optimized the injection pressure and timing in a diesel engine for better emission behavior and fuel economy with the response surface method. Alonso et al. [5] studied the feasibility of using artificial neural networks in combination with genetic algorithms to optimize the diesel engine settings. Martínez-Morales et al. [6] used artificial neural network modeling to predict the fuel consumption and Nox emission of a spark ignition (SI) engine. Asprion et al. [7] used a physics-based models to predict the NOx emissions of a diesel engine. The above literature review, it is clear the parameter optimization based on model-based methodologies has many advantages such as fast, quantitatively accurate and low cost. However, the global optimization investigation which concerned about the comprehensive performance of the engine is still scarce.

The paper took a heavy-duty NG engine as the object of optimization. After sample points was determined by central composite design method, corresponding response surface approximation models was constructed based on numerical simulation results. Then, the multi-objective and 
multi-variable optimization investigation, whose goal was to improve the output power, economy, emission and thermal load of the engine, was conducted under all conditions.

\section{Experimental setup and simulation model}

The optimization engine is a Dongfeng heavy-duty NG engine, and details of the engine are given in Table 1. Based on the system geometry structure, a one-dimensional working process model and a three-dimensional fluid dynamics and combustion in-cylinder model were respectively established with the Boost and Fire software from AVL Corporation. The one-dimensional working process model was used to provide the detailed performance parameters (like output torque, power and gas consumption rate), while the three-dimensional model was used to provide the combustion characteristic in the chamber (like cylinder pressure, combustion temperature and NOx emission).

Table 1. Engine specifications

\begin{tabular}{|l|l|}
\hline Engine Type & Six-cylinder, four stroke, water-cooling, spark ignition \\
\hline Bore x Stroke x Connecting Rod $[\mathrm{mm}]$ & 123 x 156 x 228 \\
\hline Displacement & 11.12 liters \\
\hline Compression Ratio & $10.5: 1$ \\
\hline Intake Method & Supercharge, Intercool \\
\hline Fuel Supply Mode & Multi-point Concentrated Injection \\
\hline
\end{tabular}

In order to verify the validity of the simulation model, we have compared the simulation results and experimental ones on the engine performances and cylinder pressure curves under the rated speed $(1900 \mathrm{r} / \mathrm{min})$ and the maximum torque point speed (1200r/min). The comparison shows an excellent agreement between simulation results and experimental ones. Average deviation of the engine performances simulated by one-dimensional model is $0.67 \%$, and the maximum deviation is within $3 \%$. Under all test conditions, the maximum deviation of the combustion pressure peak is no more than $1 \%$, and the phase shift of combustion is within $0.5^{\circ} \mathrm{CA}$.

\section{Experimental design method and approximation modeling}

Design of experiment

Design of experiment (DoE) could provide a reasonable and effective method to obtain sample data, and have been widely used in engineering and scientific fields [8]. Central composite design method was applied to arrange sample points in the work. This method extends the design space and can get high order information, and has many advantages such as simple design, less number of test and higher precision [9]. In this work, four factors were took into consideration, including speed, load rate, air-fuel ratio and ignition advance angle. The level design of each factor is shown in Table 2.

Table 2. The level design of each factor

\begin{tabular}{|l|l|l|l|}
\hline Factors & Maximal value & Minimum value & Central value \\
\hline Speed $[\mathrm{r} / \mathrm{min}]$ & 1900 & 1200 & 1550 \\
\hline Load rate $[\%]$ & 1000 & 25 & 62.5 \\
\hline Air-fuel ratio & 27 & 17 & 22 \\
\hline Ignition advance angle $\left[{ }^{\circ} \mathrm{CA}\right]$ & 45 & 20 & 32.5 \\
\hline
\end{tabular}

According to the experimental design, the performance parameters of NG engine in each design sampling point could be obtained by the simulation models which have been established in Section 2 .

Establishment of approximation model

This paper used polynomial function to fit the design space with the response surface method. Polynomial response surface model constructs a polynomial with a clear expression form to represent implicit functional function, which based on statistical and mathematical method. This work chose four order polynomial response surface model to construct approximation model, and its expression form is as follow, 


$$
f(x)=a_{0}+\sum_{i=1}^{n} a_{i} x_{i}+\sum_{i=1}^{n} a_{i i} x_{i}^{2}+\sum_{i=1}^{n} a_{i i i} x_{i}^{3}+\sum_{i=1}^{n} a_{i i i i} x_{i}^{4}+\sum_{i=1, j=1}^{n} a_{i j} x_{i} x_{j}
$$

Where, $n$ is the number of design variables, $x_{i, j}$ is each design variable, $i, j=1,2 \ldots \mathrm{n} ; \mathrm{a}_{0}, \mathrm{a}_{i}, \mathrm{a}_{i j}$ both are polynomial coefficients. According to the previous discussion, the response surface approximation model was constructed based on the power, economy, NOx emission and heat load (maximum combustion temperature, exhaust temperature and combustion pressure peak) of the NG engine,

$$
y_{i}=f_{i}(x 1, x 2, x 3, x 4)
$$

In $\mathrm{Eq}(2), i=1,2, \ldots, 8$, represent torque output, power, gas consumption rate, maximum combustion pressure rise rate, maximum combustion pressure, maximum combustion temperature, NOx emission and exhaust temperature.

\section{Global optimization}

The optimized control parameters of this work are air-fuel ratio and ignition advance angle, while the target parameters are torque (power), gas consumption rate (economy), NOx emission values (pollutant emission), maximum combustion temperature and exhaust temperature (thermal load). In the present study, the goal of optimization is to reduce gas consumption rate (BSFC), NOx and maximum combustion temperature $\left(\mathrm{T}_{\max }\right)$ with the premise that keeping engine in good running and enough power. The mathematical statement of the goal was stated using an objective function [10],

$$
\begin{aligned}
\max & : F=\frac{1000}{k_{1} \cdot \frac{B S F C}{B S F C_{t}}+k_{2} \cdot\left(\frac{N O x}{N O x_{t}}\right)^{2}+k_{3} \cdot \frac{T_{\max }}{T_{\max t}}} \\
\text { S.T. } & \text { Torque } \geq \text { Torque }_{t} \\
& T_{-} \text {turbine } \leq T_{-} \text {turbine }_{\lim } \\
& P_{-} \text {max } \leq P_{-} \text {max }_{\lim } \\
& P_{\text {_ }} \text { rise } \leq P_{\text {_rise }} \text { rim }_{\lim }
\end{aligned}
$$

In $\mathrm{Eq}(3), \mathrm{BSFC}_{t}, \mathrm{NOx}_{t}$ and $\mathrm{T}_{\max t}$ are the target value of the corresponding parameters. $\mathrm{k}_{\mathrm{i}}$ is the penalty factor of each target parameter. The corresponding parameters will be more toward the target value with a larger $\mathrm{k}_{\mathrm{i}}$. The constraint conditions on the engine include, the optimized output torque is

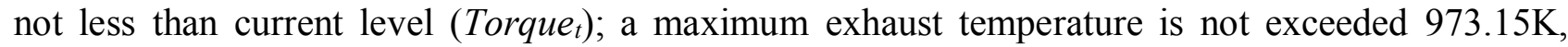
which refer to the tolerance temperature of turbine material ( $T$ _turbin lim $_{\text {) }}$; the maximum combustion pressure and pressure rise rate are respectively limited to $130 \mathrm{bar}$ and $4 \mathrm{bar} /{ }^{\circ} \mathrm{CA}$, with the consideration of engine material durability and stable operation.

As discussed above, the optimization objective function $\mathrm{Eq}$ (3) is a complex functions with multiple peak, and theses constraint function also have a very strong nonlinear. That makes it very difficult to find the optimal solution with the traditional gradient optimization or direct search method. Therefore, this work adopted multi-island genetic algorithm to search the global optimal solution. The parameter settings of multi-island genetic algorithm is shown in Table 3, and the calculation of single condition has been basically stable after the evolution of 50 generations. In a computer with Pentium E6500 2.93GHz, it takes 102 seconds to complete the optimization of single condition.

Table 3. The parameter settings of multi-island genetic algorithm

\begin{tabular}{|l|l|}
\hline Sub-population size & 10 \\
\hline Number of islands & 10 \\
\hline General evolution algebra & 50 \\
\hline Probability of crossover, mutation and migration & $1.0,0.01,0.01$ \\
\hline Interval algebra of migration & 5 \\
\hline Number of elite individuals & 1 \\
\hline
\end{tabular}




\section{Results and discussion}

Figure 1 is the optimized air-fuel ratio and ignition advance angle map for the NG engine, which have been applied with aforementioned optimization strategy and method.in order to analyze the optimization results. Figure 2-4 respectively compare the power, emission, economy and heat load performance of the NG engine before and after optimization.
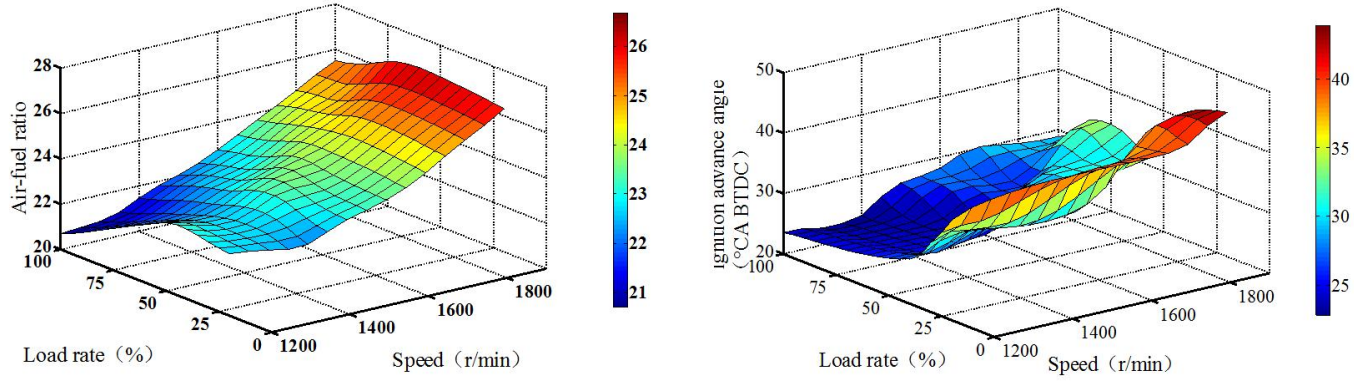

Figure 1. Air-fuel ratio and ignition advance angle map after optimization

Figure 2 shows that the power performance has a little change after optimization. In general, the torque output has increased by $0.50 \%$, while the power has an increase of $0.84 \%$ compared with the original one. Except for individual cases, the change of the power performance of most conditions are less than 3\%. Therefore, the optimization process has maintained the power performance of the NG engine very well.
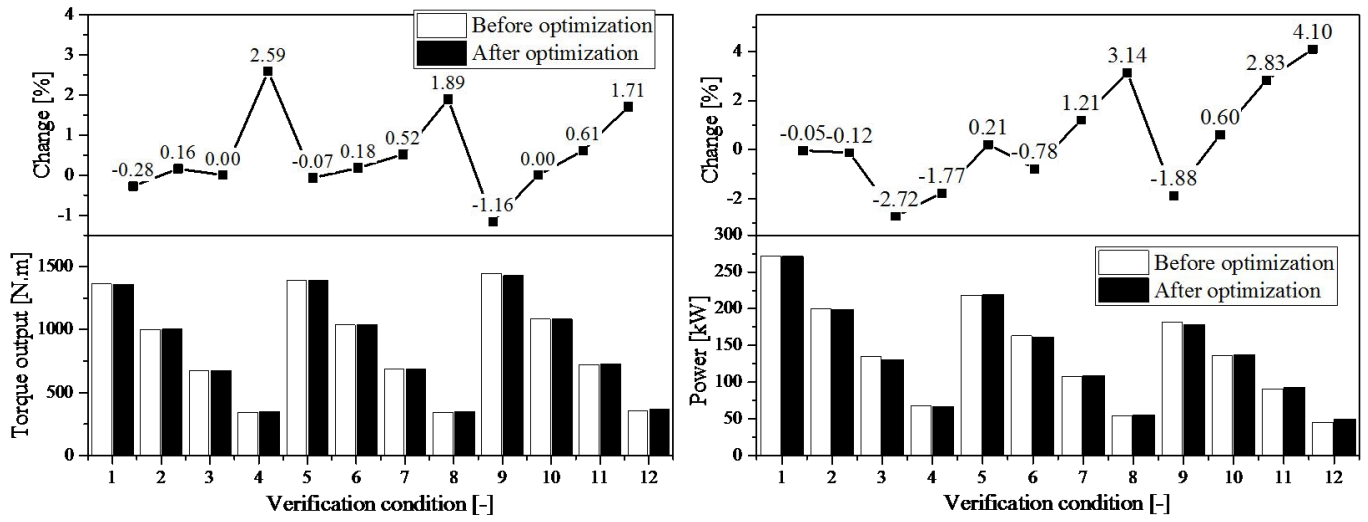

Figure 2. Comparison of the power performance of the $\mathrm{NG}$ engine before and after optimization

From the aspect of the economy and emission (Figure 3), the economy is slightly increased after optimization, and gas consumption rate has decreased by $1.10 \%$. This is because that the optimized target value of gas consumption rate is set as original one with original map in Eq (3); the further decline of gas consumption rate would affect the achievement of other optimization targets. On the other side, it has an obvious effect in the optimization on emission performance. NOx emission has decreased $30 \%$ than that before optimization in average. This demonstrates that there is a huge optimization space of emission performance on the engine control parameters.
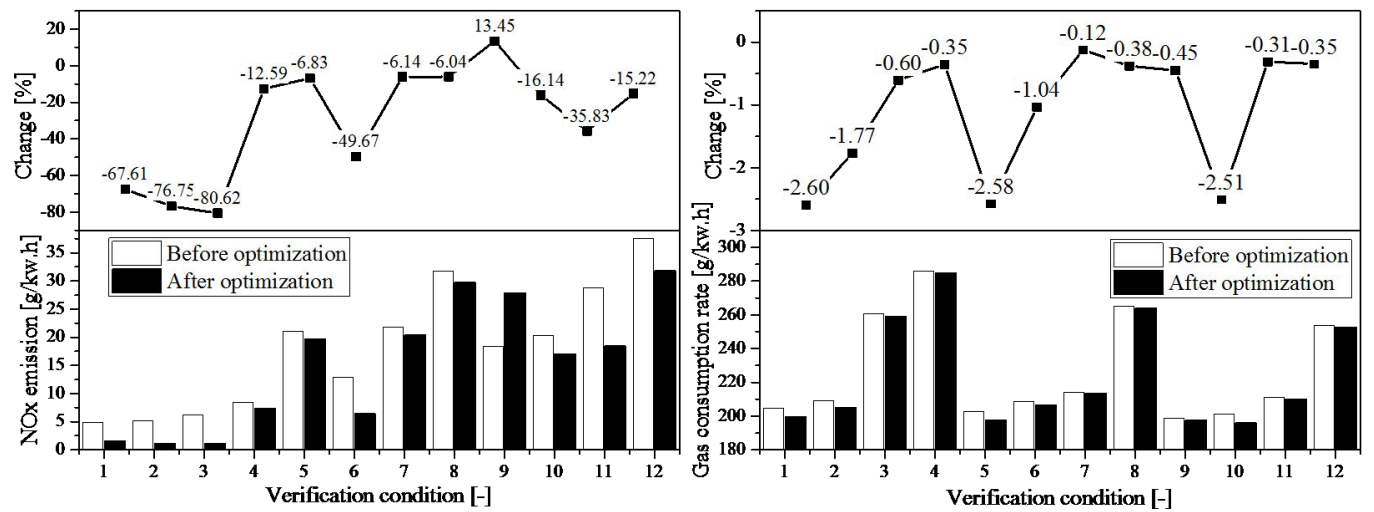

Figure 3. Comparison of the emission and economy performance of the NG engine before and after optimization 
Figure 4 shows the comparison of the heat load (maximum combustion temperature and exhaust temperature) of the NG engine before and after optimization. As an important indicator of heat load, maximum combustion temperature, has an average decline of $1.42 \%$. Besides, the reduction effect is better at conditions which have heavy heat load. For example, the maximum combustion temperature of the points in the rated speed respectively decreased $1.16 \%, 1.31 \%, 5.01 \%$ and $3.65 \%$, and the declined temperatures are $28.76 \mathrm{~K}, 32.48 \mathrm{~K}, 122.16 \mathrm{~K}$ and $88.52 \mathrm{~K}$. The exhaust temperature under all conditions are below the tolerance temperature of turbine material $(973.15 \mathrm{~K})$. In general, the heat load of the NG engine is better than the original condition.
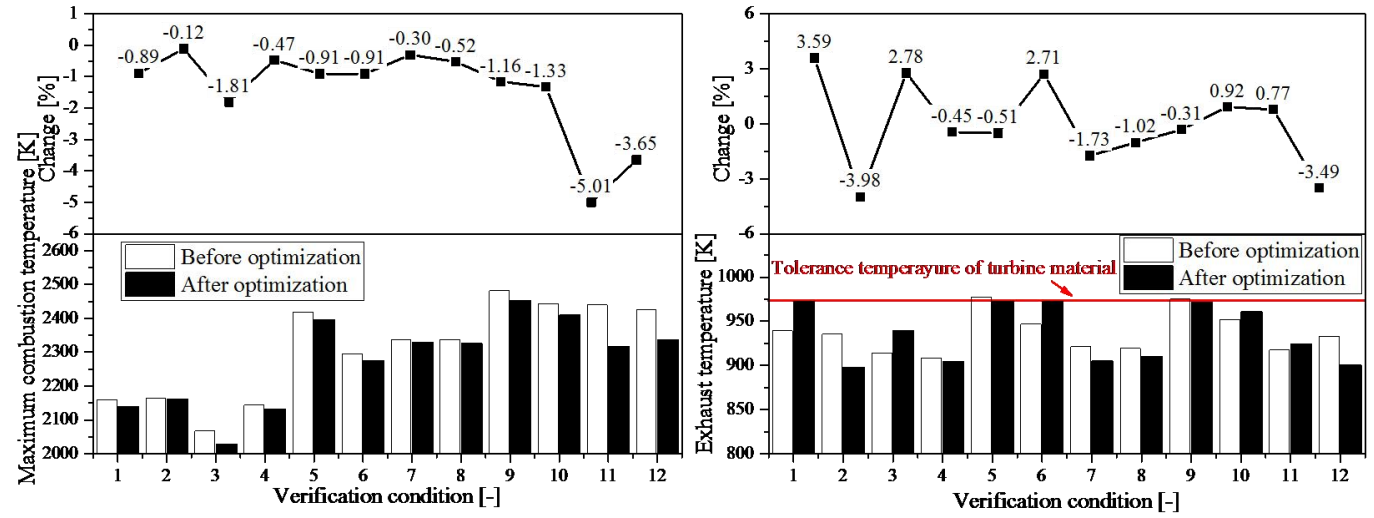

Figure 4. Comparison of the heat load of the NG engine before and after optimization

\section{Conclusion}

1) The application of approximation model to substitute experimental measurements or three dimension computational fluid dynamics simulation could greatly reduce experimental costs and improve efficiency.

2) Adopting global optimization algorithms such as multi-island genetic algorithm could be able to avoid be trapped in local optimal solution and have a good ability to solve complex optimization function under strong nonlinear constraints.

3) Establishing an appropriate multi-objective and multi-variable optimization function for the NG engine could ensure to obtain the optimal or relatively optimal control parameters under multiple operating conditions. The results show that, with the optimized control parameters, the NG engine has different degrees of improvement in the economy, emission and heat load performance under the premise of keeping the original power.

\section{References}

[1] H.M. Cho, B.-Q. He, Spark ignition natural gas engines-A review, Energy Conversion and Management, 48 (2007) 608-618.

[2] T. Korakianitis, A.M. Namasivayam, R.J. Crookes, Natural-gas fueled spark-ignition (SI) and compression-ignition (CI) engine performance and emissions, Progress in Energy and Combustion Science, 37 (2011) 89-112.

[3] M. Guerrier, P. Cawsey, The Development of Model Based Methodologies for Gasoline IC Engine Calibration, in, SAE International, 2004.

[4] D.T. Montgomery, R.D. Reitz, Optimization of Heavy-Duty Diesel Engine Operating Parameters Using A Response Surface Method, in, SAE International, 2000.

[5] J.M. Alonso, F. Alvarruiz, J.M. Desantes, L. Hernandez, V. Hernandez, G. Molto, Combining Neural Networks and Genetic Algorithms to Predict and Reduce Diesel Engine Emissions, IEEE Transactions on Evolutionary Computation, 11 (2007) 46-55.

[6] J.D. Martínez-Morales, E.R. Palacios-Hernández, G.A. Velázquez-Carrillo, Modeling engine fuel consumption and NOx with RBF neural network and MOPSO algorithm, Int.J Automot. Technol., 16 (2015) 1041-1049. 
[7] J. Asprion, O. Chinellato, L. Guzzella, Optimisation-oriented modelling of the NOx emissions of a Diesel engine, Energy Conversion and Management, 75 (2013) 61-73.

[8] D.C. Montgomery, Design and analysis of experiments, John Wiley \& Sons, 2008.

[9] T. Lundstedt, E. Seifert, L. Abramo, B. Thelin, Å. Nyström, J. Pettersen, R. Bergman,

Experimental design and optimization, Chemometrics and Intelligent Laboratory Systems, 42 (1998) 3-40.

[10] D.T. Montgomery, R.D. Reitz, Effects of Multiple Injections and Flexible Control of Boost and EGR on Emissions and Fuel Consumption of a Heavy-Duty Diesel Engine, in, SAE International, 2001. 